\title{
Chitinase-3-like Protein 1 (YKL-40) Expression in Squamous Cell Skin Cancer
}

\author{
JOANNA SALOMON $^{1}$, ALEKSANDRA PIOTROWSKA ${ }^{2}$, ŁUKASZ MATUSIAK $^{1}$, \\ PIOTR DZIĘGIEL ${ }^{2}$ and JACEK C. SZEPIETOWSKI ${ }^{1}$ \\ ${ }^{1}$ Department of Dermatology, Venereology and Allergology, Wroctaw Medical University, Wrocław, Poland; \\ ${ }^{2}$ Department of Human Morphology and Embryology, Wrocław Medical University, Wroctaw, Poland
}

\begin{abstract}
Background/Aim: YKL-40 plays a role in proliferation and differentiation of malignant cells. The aim of this study was to examine whether YKL-40 is expressed in cutaneous squamous cell carcinoma (SCC). Materials and Methods: The study was based on histologically-confirmed biopsies of cutaneous SCCs obtained from 38 patients. The tissue expression of YKL-40 was assessed using an immunohisto-chemical method. The percentage of cells showing a positive reaction as well as the intensity of the $I H C$ reaction was assessed using the immunoreactive score developed by Remmele and Stegner. Results: All samples of cutaneous SCCs showed cytoplasmic expression of YKL-40. The intensity of $Y K L-40$ expression varied between 1 and 8 points, according to the applied scale. In the majority of cancers about 10-80\% of tumor cells were positive for YKL-40. The intensity of the reaction was low (20 samples, $52.6 \%$ ) or medium ( 18 samples, 47.4\%). Conclusion: YKL-40 is expressed in cutaneous SCC. Further research is needed to establish the value of $Y K L-40$ for diagnosis and monitoring of SCC.
\end{abstract}

Chitinase-3-like protein 1 (YKL-40) is a glycoprotein discovered over 10 years ago (1). This protein belongs to the glycosyl hydrolase family 18, together with bacterial chitinases and several mammalian chitinase-like proteins (1). The biological function of YKL-40 is not fully understood; however, the studies conducted so far suggest its role in inflammation, cell differentiation, tissue remodeling and cancer growth. It is expressed and released by activated

This article is freely accessible online.

Correspondence to: Prof. Jacek Szepietowski, Department of Dermatology, Venereology and Allergology, Wrocław Medical University, ul. Chałubińskiego1, 50-368 Wrocław, Poland. Tel: +48 717842286, e-mail: jacek.szepietowski@umed.wroc.pl

Key Words: Chitinase-3-like protein, YKL-40, squamous cell skin cancer, expression, SCC. neutrophils, monocytes and macrophages (2). Various studies have reported its secretion by activated cells in inflammatory diseases, such as arthritic chondrocytes, arteritic vessels in giant cell arteritis, liver cells in viral hepatitis or atheromatous plaques and inflamed synovial membrane (3-5).

The role of YKL-40 in cancer growth is not clearly understood; however, many reports imply that this protein plays a role in proliferation and differentiation of malignant cells. Its ability to activate many pathways, including the phosphoinositide-3-kinase pathway, suggests the possibility of inducing cancer cell proliferation and acting as an antiapoptotic and survival factor (6). Moreover, this protein is an adhesion and migration factor for vascular smooth muscle cells and promotes the migration of vascular endothelial cells (7). It is also suggested that YKL-40 may influence local synthesis of hyaluronan and act as an anticatabolic factor, preserving the extracellular tissue from destruction (8). These findings lead to the conclusion that YKL-40 stimulates tumor angiogenesis, promotes inflammation in tumor microenvironment and influences remodeling of the extracellular matrix, thus providing a better understanding of its role in cancer growth and metastasis (9).

Elevated serum levels of YKL-40 have been reported in lung, bladder, ovarian, endometrial, renal, colorectal, breast cancers as well as in melanoma and other malignancies, and have been correlated with the stage of cancer and overall survival (10-18). Moreover, YKL-40 expression has been shown in the cells of many malignancies, such as melanoma, renal cell cancer, endometrial cancer, breast cancer, glial tumors, osteosarcoma, soft tissue sarcomas or squamous cell carcinomas of head, neck and esophagus (14, 17, 19-24). It has been even suggested that YKL-40 can serve as a new target for anticancer therapy $(9,25)$. To the best of our knowledge there are no studies of YKL-40 expression in non-melanoma skin cancers. Therefore, the aim of this study was to examine whether YKL-40 is expressed in the tumor tissue of cutaneous squamous cell carcinoma (SCC). 
Table I. The immunoreactive score (IRS) developed by Remmele and Stegner was used for assessment of YKL-40 expression in squamous cell skin cancer. The final result is the product of multiplication $A x B$ (0-12 points).

\begin{tabular}{ll}
\hline A. Percentage of cells expressing positive reaction & B. Intensity of the reaction \\
\hline 0: No positive cells & 0: Lack of positive reaction \\
1: Up to $10 \%$ of positive cells & 1: Low intensity of the reaction \\
2: $11-50 \%$ of positive cells & 2: Medium intensity of the reaction \\
3: $51-80 \%$ of positive cells & 3: High intensity of the reaction
\end{tabular}

4: More than $80 \%$ of positive cells

\section{Materials and Methods}

The study was retrospective in design and was based on histologically confirmed biopsies of cutaneous SCCs taken from 38 patients. These were archived formalin-fixed paraffin embedded samples. Among the patients there were 30 men and 8 women. The age of the patients varied from 55 to 94 years, with the mean age amounting to $78.8 \pm 8.8$ years. In all patients the location of the skin cancer was the head: ear lobe, lip, forehead, scalp, cheek or nose. The depth of infiltration by the cancerous tissue varied from 0.5 to $18 \mathrm{~mm}$ with the mean of $4.15 \pm 3.5 \mathrm{~mm}$. The skin lesions appeared between 6 weeks and 6 years prior to the biopsy and diagnosis (mean $1.6 \pm 1.6$ years). None of the patients had metastatic skin cancer.

The invasive ductal breast cancer tissue (two biopsies), wellknown to express YKL-40, served as a positive control. Moreover, healthy skin tissue (two biopsies) was used as an additional control. The tissue expression of YKL-40 was assessed using an immunohistochemical method. Immunohistochemical reactions (IHC) were performed on $4 \mu \mathrm{m}$-thick formalin-fixed paraffinembedded tissue sections on the detection platform Dako AutostainerLink 48. The slides were deparaffinized, rehydrated and subjected to target retrieval in the pretreatment module, PTLink (Dako, Glostrup, Denmark) at $95^{\circ} \mathrm{C}$ in Target Retrieval Solution High pH (Dako). Then the slides were cooled in TBS with $0.1 \%$ Tween (TBS-T). IHC reactions were performed using ImmPRESS Reagent Kit, Peroxidase, Anti-Goat IgG (Vector Laboratories, Burlingame, CA, USA). During the first stage, the endogenous peroxidase activity was quenched by incubation in PeroxidaseBlocking Reagent for $5 \mathrm{~min}$. After rinsing in TBS-T, the slides were incubated with Normal Horse Serum for 20 min and subsequently with anti-chitinase-3-like protein 1 immunoglobulin (R\&D Systems, catalog no. AF2599) diluted 1:50 in Antibody Diluent (for $30 \mathrm{~min}$ at room temperature). The slides were rinsed in TBS-T and incubated with secondary antibodies for $30 \mathrm{~min}$. After rinsing in TBS-T, the slides were incubated for $10 \mathrm{~min}$ with diaminobenzidine. The slides were rinsed once again in TBS-T. Then the slides were counterstained with hematoxylin, rinsed in distilled water and dehydrated in graded ethanol alcohols and xylene. The sections of squamous cell skin carcinoma, breast cancer and healthy skin tissue were processed in an identical manner.

The expression of YKL-40 was evaluated under the light microscope with 10 times and 20 times magnification. For these assessments the immunoreactive score (IRS) by Remmele and Stegner was used, which includes both the percentage of cells showing the positive reaction as well as the intensity of the IHC reaction (Table I). The assessment was performed by two independent observers. Any discrepancies were resolved by simultaneous reevaluation.

Correlations between the IHC reactions and some clinical parameters were analysed statistically. The Kolmogrov-Smirnov test was used to evaluate data distribution. All the quantitative variables were described in the form of medians and ranges. Comparisons between the groups were examined with the Mann-Whitney $U$-test or the Kruskal-Wallis test. Correlations between the variables were calculated using Spearman's rank correlation. $p$-Value less than 0.05 was considered to be statistically significant.

\section{Results}

All samples of cutaneous SCCs showed expression of YKL40. A positive IHC reaction was seen in the cytoplasm of cancer cells. In cases with visible inflammatory infiltrates within the tumor stroma, the positive IHC reaction was also observed within inflammatory cells. The intensity of YKL-40 expression in SCCs varied between 1 and 8 points, according to the applied scale (IRS). The percentage of positive cells differed a lot among the samples. In the majority of cancers about $10-80 \%$ of tumor cells showed positive IHC reaction with anti-chitinase-3-like protein 1 immunoglobulin. The intensity of the reaction was low (20 samples, 52.6\%) or medium (18 samples, 47.4\%). Examples of positive IHC reaction reflecting the expression of YKL-40 in cancer cells are shown in Figures 1 and 2. There were no samples of squamous cell carcinoma displaying strong IHC reaction with anti-chitinase-3-like protein 1 immunoglobulin. The detailed results are presented in Table II. The expression of YKL-40 in SCCs did not correlate with any of the clinical or pathological parameters (data not shown).

The ductal breast cancer tissues showed a strong expression of YKL-40. A positive cytoplasmic reaction was seen within the whole solid tissue of the cancer (Figure 3). Healthy skin biopsies presented only low epidermal YKL-40 expression mainly within the basal layer, which is a physiological pattern of staining typical for normal skin (25) (Figure 4). 


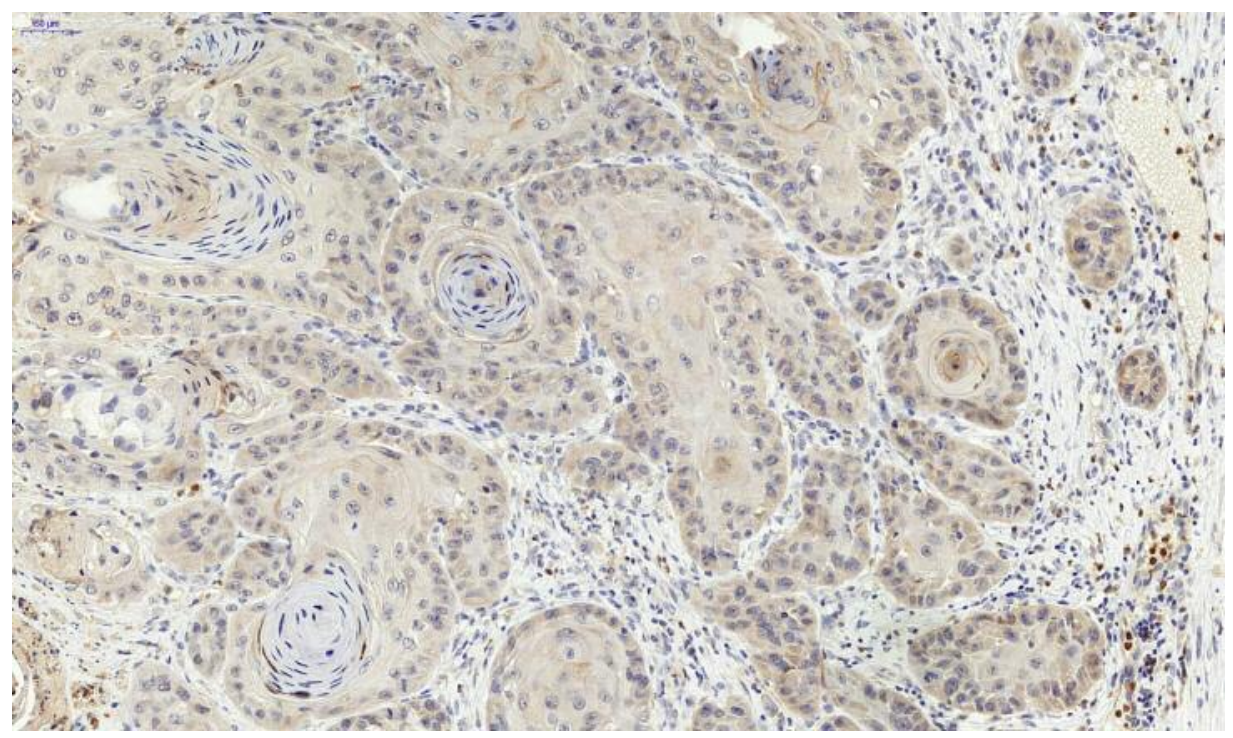

Figure 1. Positive IHC reaction for YKL-40 in squamous cell skin carcinoma. A cytoplasmic brown colored staining - a representative example scored 1+. 20× magnification.

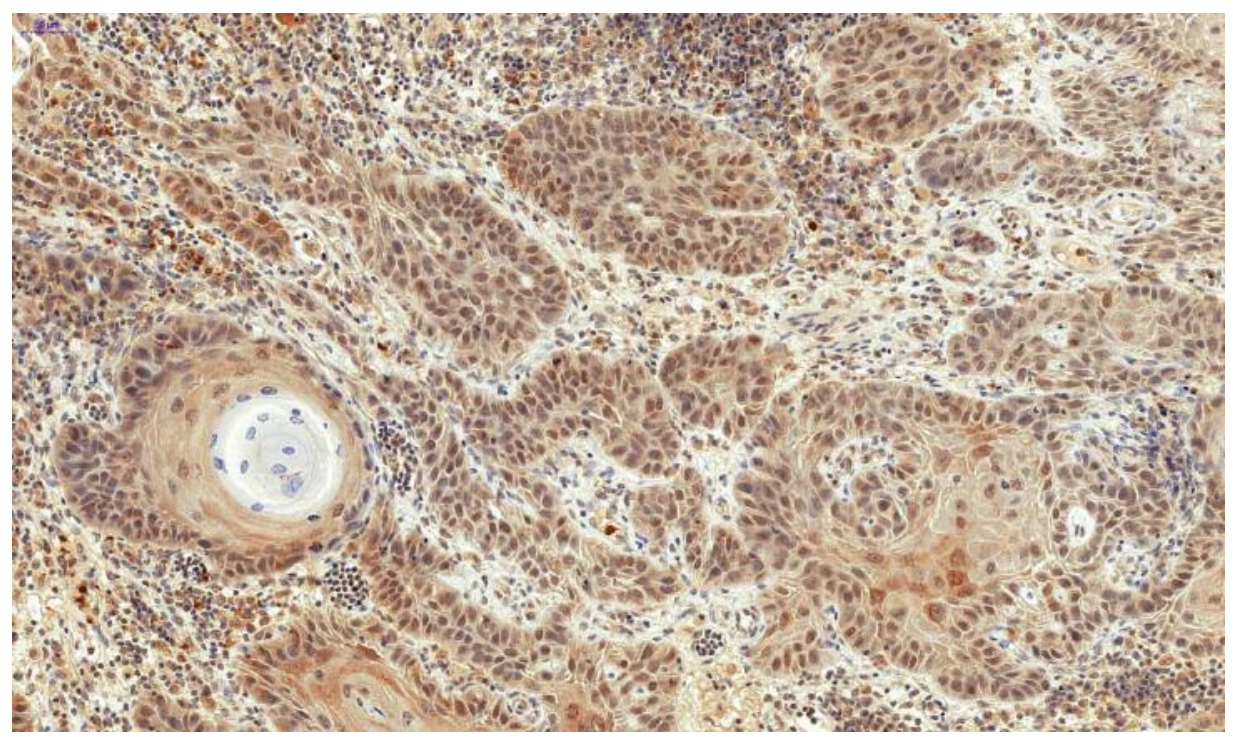

Figure 2. Positive IHC reaction for YKL-40 in squamous cell skin carcinoma. A cytoplasmic brown colored staining - a representative example scored $2+.20 \times$ magnification.

\section{Discussion}

In the present study cutaneous SCC showed cytoplasmic expression of YKL-40. However, IHC reaction did not correlate with any of the clinical parameters, which is in accordance with other reports (22). To the best of our knowledge this is the first study on the expression of YKL-40 in non-melanoma skin cancers. The studies available so far have clearly shown that many other malignant cells or cell lines express and release this protein. Positive YKL-40 expression has been reported in breast, colon, lung, prostate, thyroid, ovarian, hepatocellular, and renal cancers, as well as in glial and chondroid tumors, melanoma, osteosarcoma and soft tissue sarcomas (14, 19-22, 26-30). It was also found that squamous cell carcinomas developed within the mucous membranes of larynx, pharynx, oral cavity and esophagus show YKL-40 expression $(23,24)$. 


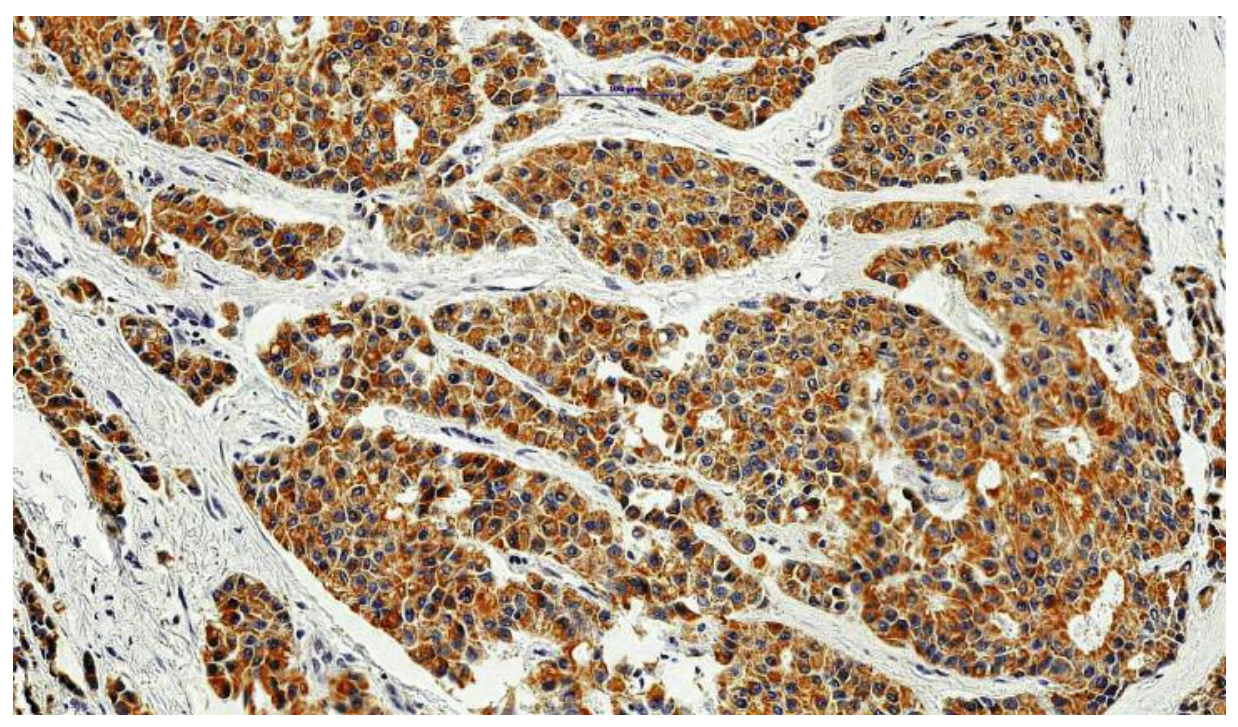

Figure 3. Positive IHC reaction for YKL-40 in ductal breast cancer as a positive control. 20x magnification.

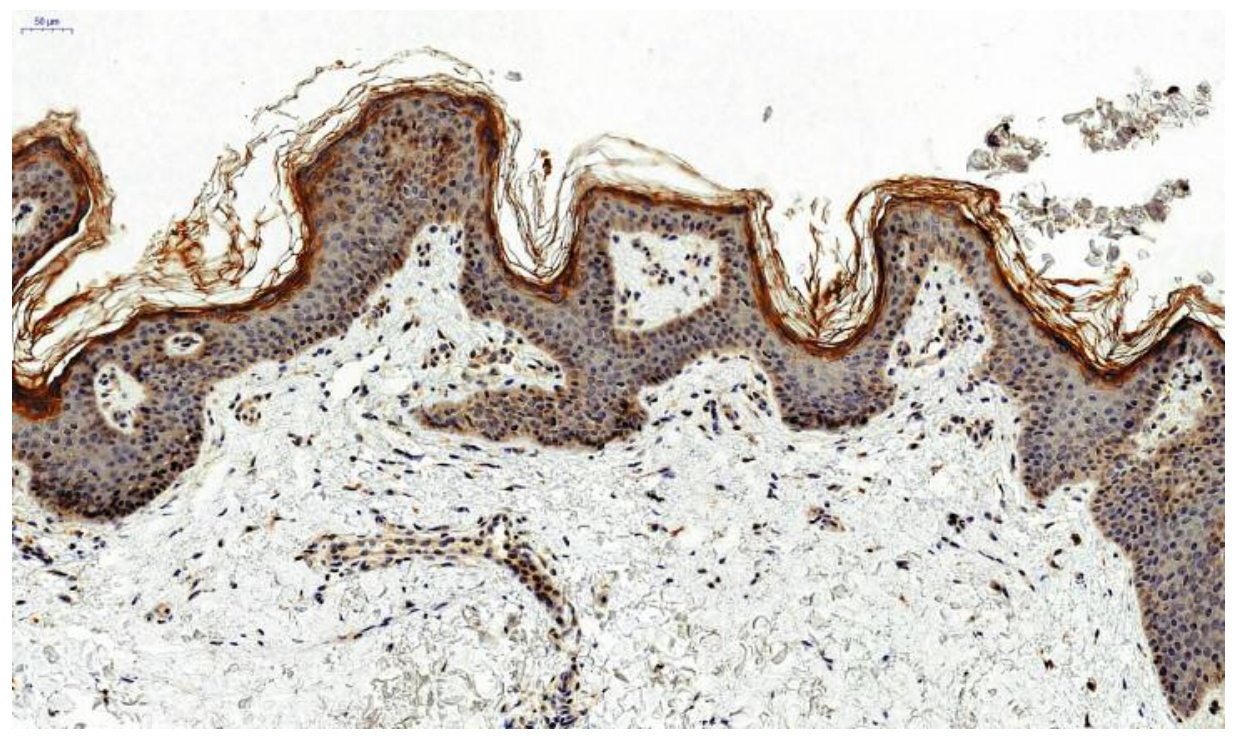

Figure 4. The picture of IHC reaction for YKL-40 in healthy skin. Low expression visible mainly in the basal epidermal layer. 20x magnification.

Table II. The expression of YKL-40 in squamous cell skin cancer (38 biopsies).

\begin{tabular}{|c|c|c|c|c|c|}
\hline \multicolumn{2}{|c|}{ The percentage of positive cells } & \multicolumn{2}{|c|}{ Intensity of IHC reaction } & \multicolumn{2}{|c|}{ Immunoreactive score according to IRS* } \\
\hline $0-10 \%$ & 3 samples $(7.9 \%)$ & Low & 20 samples $(52.6 \%)$ & 1 point & 3 samples $(7.9 \%)$ \\
\hline $11-50 \%$ & 14 samples $(36.85 \%)$ & Medium & 18 samples $(47.4 \%)$ & 2 points & 7 samples $(18.4 \%)$ \\
\hline $51-80 \%$ & 14 samples $(36.85 \%)$ & & & 3 points & 6 samples $(15.8 \%)$ \\
\hline \multirow{3}{*}{$81-100 \%$} & 7 samples $(18.4 \%)$ & & & 4 points & 11 samples $(28.9 \%)$ \\
\hline & & & & 6 points & 8 samples $(21.1 \%)$ \\
\hline & & & & 8 points & 3 samples $(7.9 \%)$ \\
\hline
\end{tabular}

*Immunoreactive score by Remmele and Stegner (0-12 points). 
In the retrospective study on head and neck squamous cell carcinomas 50 archived tissue samples were taken for immunohistochemical analysis (23). In all samples positive YKL-40 expression was found, with varying intensity of reaction scored from $1+$ to $3+$. For intensity scores $1+, 2+$ and $3+$, the percentage of reactions was $38 \%, 46 \%$ and $16 \%$, respectively. In $87 \%$ of samples the intensity of IHC reaction in tumor cells was higher than in neighboring epithelium. A positive IHC reaction was also observed in inflammatory cells present in tumor stroma. A similarly designed study on esophageal squamous cell carcinoma was conducted (24). In this report positive immunohistochemical reaction was observed in $17(85 \%)$ out of 20 samples of the cancer tissues, with varying strength of reaction (low, medium and high). In normal adjacent epithelium there was no YKL-40 expression. Furthermore, in both studies the serum concentrations of YKL40 were analyzed and it was shown that patients suffering from squamous cell carcinoma of head, neck and esophagus have significantly elevated YKL-40 serum levels which correlated with a poor prognosis and short survival.

Our report has some limitations. The retrospective nature of the study and inability to take blood samples for measurements of serum YKL-40 levels made it impossible to check the potential correlation between tissue expression and serum level of this protein. The other studies on squamous cell carcinomas of head, neck and esophagus mentioned above showed elevated serum level of this protein; however, their authors did not find any correlation between the YKL40 tissue expression and its serum level (24).

This study showed that YKL-40 is expressed in cutaneous SCCs, both in tumor cells and in inflammatory infiltrates in tumor stroma. This phenomenon may potentially influence the serum YKL-40 level in these patients. SCC is rarely lifethreatening; however, it may be metastatic. All the patients who underwent the therapy require long term monitoring for relapses and metastases. If SCC is a significant source of YKL-40 release, the serum YKL-40 level could be a candidate for a biomarker potentially used in patients' follow up after the treatment. There is a need for further prospective research to establish the value of YKL-40 for diagnosis of SCC as well as for monitoring of relapses and metastases.

\section{References}

1 Aronson NN, Blanchard CJ and Madura JD: Homology modeling of glycosyl hydrolase family 18 enzymes and proteins. J Chem Inf Comput Sci 37: 999-1005, 1997.

2 Hashimoto S, Suzuki T, Dong H-Y, Yamazaki N and Matsushima $\mathrm{K}$ : Serial analysis of gene expression in human monocytes and macrophages. Blood 94: 837-844, 1999.

3 Johansen JS, Baslund B, Garbarsch C, Hansen M, Stoltenberg M, Lorenzen I and Price PA: YKL-40 in giant cells and macrophages from patients with giant cell arteritis. Arthritis Rheum 42: 2624-2630, 1999.
4 Volck B, Johansen JS, Stoltenberg M, Garbarsch C, Price PA, Ostergaard M, Ostergaard K, Løvgreen-Nielsen P, Sonne-Holm $S$ and Lorenzen I: Studies on YKL-40 in knee joints of patients with rheumatoid arthritis and osteoarthritis. Involvement of YKL-40 in the joint pathology. Osteoarthritis Cartilage 9: 203$214,2001$.

5 Shackel NA, McGuinness PH, Abbott CA, Gorrell MD and McCaughan GW: Novel differential gene expression in human cirrhosis detected by suppression subtractive hybridization. Hepatology 38: 577-588, 2003.

6 Recklies $\mathrm{AD}$, White $\mathrm{C}$ and Ling $\mathrm{H}$ : The chitinase 3-like protein human cartilage 39 (HC-gp39) stimulates proliferation of human connective-tissue cells and activates both extracellular signalregulated kinase- and protein kinase B-mediated signaling pathways. Biochem J 365: 119-126, 2002.

7 Malinda KM, Ponce L, Kleinman HK, Shackelton LM and Millis AJT: Gp38k, a protein synthesized by vascular smooth muscle cells, stimulates directional migration of human umbilical vein endothelial cells. Exp Cell Res 250: 168-173, 1999.

8 Meyer MF and Kreil G: Cells expressing the DG42 gene from early Xenopus embryos synthesize hyaluronian. Proc Natl Acad Sci USA 93: 4543-4547, 1996.

9 Kzhyshkowska J, Yin S, Liu T, Riabov V and Mitrofanova I: Role of chitinase-like proteins in cancer. Biol Chem 397: 23147, 2016.

10 Kırankaya Güneş A, Gül Ş, Tutar N, Özgül MA, Çetinkaya E, Zengi $\mathrm{O}$ and Onaran $\mathrm{H}$ : The place of YKL-40 in non-small cell lung cancer. Tuberk Toraks 62: 273-278, 2014.

11 Yasar O, Akcay T, Obek C and Turegun FA: Diagnostic potential of YKL-40 in bladder cancer. Urol Oncol 34: 257.e 19-24, 2016.

12 Chen J, Liu X, Pan YQ, He BS, Ying HQ, Sun HL, Deng QW, Lin K, Peng HX and Wang SK: Analysis of diagnostic value of YKL-40 in ovarian cancer. Int J Gynecol Cancer, 2016. [Epub ahead of print]

13 Cheng D, Sun Y and He H: Diagnostic role of circulating YKL40 in endometrial carcinoma patients: a meta-analysis of seven related studies. Med Oncol 31: 326, 2014.

14 Vom Dorp F, Tschirdewahn S, Niedworok C, Reis H, Krause H, Kempkensteffen C, Busch J, Kramer G, Shariat SF, Nyirady P, Rübben $\mathrm{H}$ and Szarvas T: Circulating and Tissue Expression Levels of YKL-40 in Renal Cell Cancer. J Urol 195: 1120-1125, 2016.

15 Johansen JS, Christensen IJ, Jørgensen LN, Olsen J, Rahr HB, Nielsen KT, Laurberg S, Brünner N and Nielsen HJ: Serum YKL-40 in risk assessment for colorectal cancer: a prospective study of 4,496 subjects at risk of colorectal cancer. Cancer Epidemiol Biomarkers Prev 24: 621-626, 2015.

16 Wang D, Zhai B, Hu F, Liu C, Zhao J and Xu J: High YKL-40 serum concentration is correlated with prognosis of Chinese patients with breast cancer. PLoS One 7: e51127, 2012.

17 Krogh M, Christensen I, Bouwhuis M, Johansen JS, Nørgaard P, Schmidt H, Hansson J, Suciu S, Eggermont AM and Bastholt L; Nordic Melanoma Group and EORTC Melanoma Group: Prognostic and predictive value of YKL-40 in stage IIB-III melanoma. Melanoma Res 26: 367-376, 2016.

18 Corradi M, Goldoni M, Alinovi R, Tisea M, Ampollin L, Bonini S, Carbognani P, Casalini A and Mutti A: YKL-40 and mesothelin in the blood of patients with malignant mesothelioma, lung cancer and asbestosis. Anticancer Res 33: 5517-5524, 2013. 
19 Schmidt H, Johansen JS, Gehl J, Geertsen P, Fode K and von der Maase H: Elevated serum level of YKL-40 in an independent prognostic factor for poor survival in patients with metastatic melanoma. Cancer 106: 1130-1139, 2006.

20 Johansen JS, Jensen BV, Roslind A, Nielsen D and Price PA: Serum YKL-40, a new prognostic biomarker in cancer patients? Cancer Epidemiol Biomarkers Prev 15: 194-202, 2006.

21 Harving ML, Christensen LH, Ringsholt M, Lausten GS and Petersen MM: YKL-40 expression in soft-tissue sarcomas and atypical lipomatous tumors. An immunohistochemical study of 49 tumors. Acta Orthop 85: 195-200, 2004.

22 Kazakova MH, Staykov DG, Koev IG, Kitov BD and Sarafian VS: A comparative study of LAMPs and YKL-40 tissue expression in glial tumors. Folia Med (Plovdiv) 56: 194-198, 2014.

23 Roslind A, Johansen JS, Christensen IJ, Kiss K, Balslev E, Nielsen DL, Bentzen J, Price PA and Andersen E: High serum levels of YKL-40 in patients with squamous cell carcinoma of the head and neck are associated with short survival. Int J Cancer 122: 857-863, 2008.

24 Zheng X, Xing S, Liu XM, Liu W, Liu D, Chi PD, Chen H, Dai SQ, Zhong Q, Zeng MS and Liu WL: Establishment of using serum YKL-40 and SCCA in combination for the diagnosis of patients with esophageal squamous cell carcinoma. BMC Cancer 14: 490, 2014.

25 Ringsholt M, Høgdall EV, Johansen JS, Price PA and Christensen LH: YKL-40 protein expression in normal adult human tissues an immunohistochemical study. J Mol Histol 38: 33-43, 2007.
26 Kazakova MH and Sarafian VS: YKL-40-a novel biomarker in clinical practice? Folia Med (Plovdiv) 51: 5-14, 2009.

27 Kang EJ, Jung H, Woo OH, Park KH, Woo SU, Yang DS, Kim AR, Lee JB, Kim YH, Kim JS and Seo JH: YKL-40 expression could be a poor prognostic marker in the breast cancer tissue. Tumour Biol 35: 277-286, 2014.

28 Xiao XQ, Hassanein T, Li QF, Liu W, Zheng YH and Chen J: YKL-40 expression in human hepatocellular carcinoma: a potential biomarker? Hepatobiliary Pancreat Dis Int. 10: 605610, 2011.

29 Daugaard S, Christensen LH and Høgdall E: Markers aiding the diagnosis of chondroid tumors: an immunohistochemical study including osteonectin, bcl-2, cox-2, actin, calponin, D2-40 (podoplanin), mdm-2, CD117 (c-kit), and YKL-40. APMIS 117: 518-525, 2009.

30 Hao H, Wang L, Chen H, Xie L, Bai T, Liu H and Wang D: YKL-40 promotes the migration and invasion of prostate cancer cells by regulating epithelial mesenchymal transition. Am J Transl Res 9: 3749-3757, 2017.
Received May 16, 2018

Revised June 25, 2018

Accepted June 26, 2018 